\title{
Políticas industriais no Brasil: da necessidade à dificuldade de sua implementação
}

\section{Resumo}

O estímulo à competição, à intensificação no ritmo da incorporação do progresso técnico na produção e à reestruturação das indústrias marcaram as forças econômicas mundiais na última década. Todos esses fatores provocaram um movimento de preocupação nas empresas com a produtividade e melhoria dos seus produtos e serviços obtidos, freqüentemente, com a internacionalização e globalização de seus manufaturados inseridos num modelo pós-fordista de estruturação e organização das empresas.

Estes acontecimentos levam-nos a pensar, muitas vezes, no sentido e no conteúdo de uma política industrial num momento em que empresas e nações centralizam seus esforços na conquista da competitividade. Este artigo apresenta algumas consideraçōes sobre este tema.

\section{Abstract}

The stimulation to the competition, the intensification in the incorporation's rhythm of technique progress in the production and industries restructure pointed the economical worldly forces in this last decade. All these factors concerned preoccupation movement in enterprises with the productivity and amelioration of their products and services obtained, frequently, with the internationalize operations and globalization of production with commercialize of manufacturing products inserted post-Ford model of business structure and organization.

These happenings take us, very often, to think over the sense and contents of industrial politics at a moment when business and nations centralize efforts to conquer of competitiveness. This article presents some regards about this theme.

\section{Política industrial: conteúdos gerais}

Em uma primeira aproximação, política industrial trata de uma visão estratégica do que se deseja para o futuro industrial do país, que, de acordo com Pinheiro (1994), é definida como "o conjunto de medidas tomadas pelo setor público com a finalidade de aumentar o valor presente do produto oriundo da indústria". Assim, o produto industrial seria elevado, se houvesse incrementos no montante de insumos (capital, trabalho, matéria-prima), melhorias em suas qualidades ou aumentos da produtividade total dos fatores que, via progresso técnico ou maior eficiência gerencial, leva a aumentos de eficiência na linha de produção.

Quanto aos seus objetivos (STRACHMAN, 1999), a ênfase de uma política industrial deve estar na busca da eficiência e nos ganhos de competitividade, aceitando-se, sob alguns aspectos, a premissa de que é possível aumentar o nível agregado de emprego e de bem-estar por meio da intervenção governamental (BONELLI, 1994), desde que seja desenhado um projeto de desenvolvimento industrial para o país.

No passado recente, as políticas públicas voltadas para o desenvolvimento industrial utilizaram-se de instrumentos de ação básicos, classificados em quatro categorias, quais sejam, fiscais, monetários, cambiais e de intervenção direta, mas na discussão recente sobre políticas industriais, uma questão usual é a distinção

\footnotetext{
* Mestre em Economia Política pela Pontifícia Universidade Católica de São Paulo. Professor dos cursos de Economia e Administração de Empresas da Universidade Paulista. Professor do curso de Administração de Empresas com Habilitação em Comércio Exterior das Faculdades Integradas "Campos Salles".
} 
entre políticas verticais/setoriais e políticas horizontais/gerais.

Uma estratégia de desenvolvimento setorial consistiria essencialmente da identificação de obstáculos que se interpõem à realização do potencial competitivo do setor analisado, e na definição de um conjunto de ações programáticas necessárias para superar estes obstáculos, escalonados no tempo.

No Brasil, a ação governamental via políticas setoriais/verticais se desenvolveu no período da industrialização por substituição de importações, no qual alguns setores industriais ou empresas específicas eram alvos de mecanismos indutores do investimento baseados na proteção, na promoção e na regulação destes mercados. São políticas mais discriminatórias do ponto-de-vista da seleção de quem será o maior beneficiado de uma política industrial ativa. Segundo Frischtak (1993) e Bonelli (1994), a base destas políticas está em medidas setoriais que incluem:

- escolha de segmentos a estimular, ou seja, os "vencedores";

- criação de incentivos fiscais e creditícios aos segmentos escolhidos;

- imposição de requisitos de nacionalização e de compra das estatais como instrumentos de uma política ativa setorialmente discriminatória e;

- uso de câmaras setoriais para coordenar a lógica empresarial e criação de foros de negociação em segmentos selecionados.

Já a ação governamental via políticas gerais/horizontais tem alcance generalizado em relação a todos os segmentos industriais e não-industriais instalados ou a instalar no país. Envolve basicamente medidas que visam ao aumento da eficiência (e diminuição de custos presentes e/ou futuros) do sistema industrial e econômico como um todo, ou seja, são medidas que estabelecem pré-condições à competitividade sistêmica ${ }^{1}$, e não apenas setorial.

O cerne das políticas genéricas, enquanto ações de desregulamentação e suporte de merca- do, passa, primeiramente, pela promoção de uma política de competição entre produtores domésticos visando à competição frente as importações de manufaturados, fixando, desta forma, instrumentos de proteção tarifária moderada e declinante no tempo, para, em segundo lugar, implementar políticas de competição nos mercados internacionais, ao colocar o exportador nacional em condições de igualdade com seus concorrentes nestes mercados. Mais especificamente (FRISCHTAK, 1993), essas políticas de competição dependem de um conjunto básico de providências, a saber:

- melhoria de infra-estrutura portuária-ferroviária-rodoviária;

- redução de impostos de importação sobre matérias-primas e/ou bens-de-capital;

- concessão de incentivos de crédito/financiamento com base em indicadores de desempenho; - instituição de programas de treinamento e de melhoria educacional para formação profissional;

- agilização dos procedimentos de transferência de tecnologia;

- abertura de créditos à exportação;

- instituição de políticas antitruste e instituição de políticas de concorrência e de proteção contra práticas desleais de comércio exterior, bem como controles ao exercício de poder de monopólio;

- reforma tributária;

- proteção ao consumidor;

- proteção ao meio ambiente.

$\mathrm{Na}$ caracterização das políticas industriais setoriais ou gerais discute-se, no âmbito teórico (ERBER; CASSIOLATO, 1997), modelos de desenvolvimento industrial, dentre eles, o modelo neoliberal radical, o modelo neoliberal reformista, o modelo neo-desenvolvimentista e o modelo social democrata.

No modelo neoliberal radical, o único com característica horizontal/geral, ficaria a cargo do mercado, através do sistema de preços, a perfei-

\footnotetext{
${ }^{1}$ Para um maior aprofundamento, ver STAMER, Jörg Meyer. Competitividade sistêmica: quais são seus fatores e como se relacionam. Ela pode funcionar no Brasil? In: MATHIEU, H. A nova política industrial: o Brasil no novo paradigma. São Paulo: Marco Zero, 1996: p 23-42.
} 
automobilística, estava ainda por ser implantada. Por outro lado, as grandes empresas industriais dos países centrais, já recuperadas da Segunda Guerra Mundial, transformam-se em gigantescos empreendimentos dentro de seus países e estão prontas para se tornarem empresas multinacionais industriais. Após se instalarem noutros países centrais, logo escolheriam alguns países periféricos como o Brasil (BRESSER PEREIRA, 1986), dando continuidade ao processo de substituição de importações de bens de consumo durável.

No final dos anos 60 e início dos 70, os objetivos gerais da política industrial se modificam, voltando-se para atividades orientadas para exportação, com estímulos à criação e expansão da capacidade somente para conquista de mercados externos. Ao final dos anos 80 , a busca de competitividade se tornará objetivo central da política do governo (FRISCHTAK, 1993), e o padrão de industrialização passa a ser condicionado pelas novas tecnologias de microeletrônica, informática, telecomunicações, automação, pela busca de novos materiais e de energias renováveis e pela biotecnologia. Os anos 80, foram ainda marcados pela ruptura do crescimento econômico das décadas anteriores, combinado com elevados índices de inflação e possíveis tentativas de estabilização, bem como o chamado esgotamento do modelo substitutivo de importações.

Chamados também de década perdida, estes anos, principalmente o período entre os anos 1980-85, foram notáveis no que diz respeito à ausência de políticas industriais (LACERDA, 1998) como promotoras de desenvolvimento econômico que, combinado com um quadro de instabilidade macroeconômica, gerou como conseqüência queda nas taxas de investimento agregado, tanto no setor público quanto no privado, provocada também por pressões de crise de financiamento da economia, elevado processo inflacionário, altas taxas de juros internas ocasionando riscos nos investimentos produtivos, bem como aumentando a incerteza quanto ao futuro.

As medidas de estímulo à indústria adotadas no Brasil até meados da década de 1980 foram eficazes para o crescimento da produção, porém ineficazes tanto para gerar ganhos de competitividade, quanto para avanços de eficiência em termos de redução de custos. Ao final desta década, havia uma certa percepção por parte dos agentes produtores e dos policy makers que o modelo deveria ser revisto, pois a queda dos investimentos produtivos gerou uma séria restrição ao crescimento sustentado, caracterizado pelo movimento de stop and go no nível de atividade. À medida que nos aproximamos da década de 1990, a política industrial confunde-se mais e mais com a política comercial do País. A ênfase na liberalização comercial, já no governo Collor, representa uma ruptura em relação às políticas industrial e comercial brasileiras anteriores a esta década.

Dada a instabilidade macroeconômica dos anos 80 , muitos setores da economia brasileira, se comparados aos padrões internacionais, encontravam-se em perfeito atraso tecnológico, tanto no que diz respeito à obsolescência das máquinas e equipamentos, quanto aos métodos administrativos-gerenciais. Diante de tal quadro, surgiu a necessidade da definição de uma política industrial efetiva que encaminhasse a economia brasileira na busca da recuperação do atraso tecnológico. Em junho de 1990, então com o presidente Fernando Collor de Mello, temos as diretrizes gerais para a Política Industrial e de Comércio Exterior - PICE, tendo como objetivo central o aumento da eficiência na produção e comercialização de bens e serviços, a ser atingido através da modernização e reestruturação da indústria brasileira.

A PICE repousava no pressuposto de que a estabilidade econômica seria atingida com procedimentos ortodoxos centrados no controle da moeda e no controle da inflação, mas o seu fracasso na primeira fase do governo Collor levou ao abandono de tal política. Segundo Erber e Cassiolato, (1997), "o fim da PICE assinala o ocaso do modelo desenvolvimentista no âmbito governamental e a completa hegemonia do modelo liberal, com sua ênfase ainda na estabilização de preços e também nas reformas institucionais que facilitem a ação dos mercados". 
Para tanto, adotou-se como estratégias (LACERDA, 1998): redução de proteção tarifária conjugada com eliminação de mecanismos de defesa comercial; exposição da indústria nacional à competição internacional, visando a melhoria da qualidade e preços dos produtos no mercado interno; fortalecimento de segmentos competitivos, propiciando especialização da produção; capacitação tecnológica da empresa nacional, apoiando indústrias de tecnologia de ponta e reestruturação produtiva e competitiva da indústria nacional.

Paralelamente à questão conjuntural recessiva proporcionada pelos Planos Collor I e II, este quadro de liberalização comercial implicou, por parte das empresas nacionais, um forte processo de ajuste. Tal ajustamento obrigou algumas empresas a concentrarem-se em linhas de produtos competitivos, reduzindo ao máximo a diversificação de sua produção, via terceirização de algumas atividades e implementação de programas de qualidade e produtividade.

Tomando-se por base as empresas produtoras de bens de consumo não durável, bem como as empresas de menor porte, verificou-se no período anteriormente mencionado um baixo nível de produtividade advindo dos elevados custos de produção, ocasionando, então, limitação da capacidade de competição destas firmas. Tal baixa da competitividade deve-se, de acordo com Lacerda (1998), "principalmente", à baixa flexibilidade das empresas, para alterarem sua produção na busca de qualidade e melhor desempenho de seus produtos, conjugada ainda com a falta de "prontidão dessas empresas para atender às demandas por novos lançamentos, sofisticação, qualidade e diversidade de bens e serviços ofertados".

Além destes fatores endógenos à empresa na busca de produtividade e competitividade, existiam ainda fatores exógenos, pois não houve por parte do governo uma adaptação macroeconômica, no que diz respeito à competitividade sistêmica, que propiciasse ao produtor local um ambiente favorável e/ou equivalente aos concorrentes internacionais. Fatores como taxa de juros, carga tributária, infraestrutura técnico-científico-educacional e burocracia do setor público, entendidos então como o chamado "Custo Brasil", colocam-se como gargalos ou entraves para a indústria doméstica concorrer com a indústria estrangeira, e neste caso não há esforço, do ponto de vista microeconômico, que possa vir a compensar tal disparidade.

$O$ fato de que a política industrial tenha no Brasil tantos pontos em comum com a de comércio exterior é, necessariamente verdade, em um país que experimentou um rápido processo de abertura. Mas isto não exclui o uso de instrumentos e políticas tanto verticais como horizontais recomendados pela experiência internacional de diversos países na promoção de política industrial. Afinal, não é suficiente se utilizar apenas da liberalização comercial como mecanismo de promoção de eficiência e da produtividade na produção de produtos e serviços, pois ela é um remédio amargo e mostra-se ineficaz, se usada apenas com este objetivo (BONELLI, 1994).

\section{Linhas gerais para uma política industrial no Brasil}

Tendo em mente que a chamada globalização da economia e o novo paradigma produtivo nela implícito exigem tanto das empresas, como das nações, novos métodos de organização da produção, e que só sobreviverá aquele que se adaptar às novas regras, ou seja, empresas e países precisam ser competitivos frente à concorrência acirrada advinda do processo de abertura das economias, a chave para esta sobrevivência e expansão de economias nacionais e de suas empresas está nos ganhos de produtividade. Diante disto, com o auxílio de técnicos e instituições poderemos levantar as grandes linhas que deveriam reger a política industrial no Brasil presente.

Para que seja formulada uma política industrial é necessário que se tenha um projeto de indústria e uma visão de sua configuração futura. No Brasil (PINHEIRO, 1994), esta visão seria de uma indústria competitiva, integrada na economia mundial, crescentemente formada por empresas que utilizem trabalho qualificado, produzindo, via processos eficientes e limpos, bens de alto valor agregado e com capacidade sustentada de criação 
de emprego, o que resultaria em aumento de produtividade dos recursos humanos, aumento da renda e do consumo da população.

A consolidação desta indústria depende, porém, de vários elementos (FRISCHTAK, 1999), como, por exemplo, de um ambiente econômico caracterizado por estabilidade de preços e regras, de um conjunto de projetos de investimentos em infra-estrutura física, tecnológica, educacional e na logística de comércio internacional e de mecanismos de cooperação e integração como pontos de trocas de informação.

A atitude industrial englobaria também uma política de mobilização dos ativos tecnológicos públicos e criação de arranjos integrados desses ativos com o setor produtivo. A forma que essa integração tomaria incluiria a assistência de natureza técnica e gerencial a pequenos e médios empresários, prestada por docentes e pesquisadores, orientada para a criação de condições materiais que apóiem os esforços empresariais emergentes na fronteira do conhecimento e da criatividade.

No contexto de liberalização econômica, a política industrial a ser adotada pelo Brasil necessitaria de maior exposição à competição externa e interna, com aumento simultâneo da competitividade da indústria (BONELLI, 1994). Para elevar a eficiência do sistema industrial como um todo, seria necessário atender aos principais determinantes de competitividade industrial, observando-se que: (a) alguns segmentos operam sob distintos padrões de eficiência, e os que operam com muita eficiência necessitam de pouco apoio, seja via reconversão para outras atividades ou atingindo níveis mais elevados de competitividade; (b) há no país limitada capacidade de gerar progresso técnico endogenamente no curto prazo, já que o esforço na geração autônoma de progresso técnico é necessariamente de longo prazo; (c) a pouca disposição revelada pela indústria brasileira quanto a lançar novos produtos ou a criar novos processos produtivos nada tem a ver com uma falta de apetite inovador dos empresários, mas sim com a inexpressiva atividade governamental no que diz respeito ao apoio para desenvolvimento científico e tecnológico.
De acordo com Anita Kon (1996), seria necessária a implementação de uma política industrial efetiva com perfeito entendimento de quais setores e quais agentes envolvidos seriam contemplados com as medidas de política e programação econômicas.

No que se refere à abrangência setorial, o conceito de indústria deveria ser repensado, englobando, além das atividades secundárias, também as terciárias da economia, incluindo-se a modernamente denominada indústria de serviços, que fornece parte da infra-estrutura de apoio à operacionalização das demais atividades.

Para Coutinho (1998), haveria no Brasil espaço para uma política industrial moderna e baseada na parceria entre empresários, trabalhadores e governo, como fator decisivo para viabilizar a sustentação da política macroeconômica. Uma política industrial implementada por modernos instrumentos de comércio exterior seria fundamental para estimular exportações e conter importações predatórias.

Mais do que a tentativa de implementação de diversos instrumentos de política econômica, notadamente aqueles destinados a setores industriais, Coutinho (1998) prega um debate entre sociedade e governo, em torno de uma agenda de medidas para estruturar um ministério forte e articulado, privilegiando o diálogo e a parceria entre os agentes envolvidos na criação de meios de financiamento e de capitalização, para que as empresas nacionais participem do processo de exportação de mercadorias e geração de divisas. Em busca deste debate entre sociedade e governo, Kapaz (1996) acredita na criação de um "Conselho Nacional de Política Industrial", onde deveria ser efetuada a conciliação de políticas públicas de outras áreas, como agricultura, ciência e tecnologia com a política industrial.

Para Celso Lafer (1999), não bastaria só isto. Torna-se ainda necessária uma maior articulação entre os governos estaduais, para que esses façam parte de agentes condutores da política industrial, no tocante à incorporação da pequena e média empresa no sistema produtivo, já que este tipo de empresa pode, em primeiro lugar, ajudar na melhoria das oportunidades de emprego e renda da so- 
ciedade, em segundo lugar, promover a difusão de novos métodos organizadores da produção quanto às inovações e, em terceiro lugar, por permitir ainda às grandes empresas o benefício da redução de custos e aumento da produtividade e competitividade através da terceirização e subcontratação.

Desta articulação intergovernamental sairia o desenvolvimento e a consolidação de clusters e pólos tecnológicos, a partir de vocações regionais identificadas por tornar-se uma atividade de muita importância para a economia brasileira, quer pela via da integração de uma constelação de empresas de menor porte no processo produtivo de grandes empresas, quer pela vertente de grupamento autônomo de micro, pequenas e médias empresas que operem no mesmo segmento de atividade.

Sustenta ainda que o desenvolvimento de clusters constitui um grande instrumento de intervenção governamental que se traduzirá em política de desenvolvimento local ou regional, já que, enquanto os eixos articulam os grandes espaços macrorregionais, os clusters multiplicam, nos espaços adjacentes, as energias geradas por um conjunto de empresas de um mesmo ramo de negócio, que atraem fornecedores e prestadores de serviços, ao mesmo tempo em que criam oportunidades para atividades de comercialização.

\section{Considerações finais}

Sendo assim, temos, com o desenvolvimento deste, que existe espaço para uma maior atuação do Estado quanto ao favorecimento das empresas industriais. Não pregamos aqui um favorecimento paternalista, como o ocorrido no Brasil no período passado. Acreditamos que, se algumas iniciativas fossem tomadas pelos governantes, seja através de políticas verticais ou horizontais, inseridas num modelo de desenvolvimento industrial bem delineado e de comum acordo com a sociedade, tanto no âmbito nacional como no regional, poderiam promover um maior nível de competitividade para tais empresas.

Infelizmente, hoje, a discussão das políticas industriais parece não ser alvo de preocupação por parte dos dirigentes da nação, dadas as práticas neoliberais implementadas no país a partir do início da década de 90, atreladas à manutenção e sustentação de uma estabilidade monetário-financeira dentro de um ambiente macroeconômico extremamente recessivo. Se, efetivamente, existir uma preocupação nesta área, poderão ser conjugadas as diversas sugestões elencadas neste exercício.

\section{REFERÊNCIAS BIBLIOGRÁFICAS}

BONELLI, Regis. Linhas gerais para política industrial. In: IPEA. O Brasil no fim do século: desafios e propostas para a ação governamental. Rio de Janeiro: IPEA, 1994. p.245-256.

BRESSER PEREIRA, Luiz Carlos. Economia brasileira: uma introdução crítica. São Paulo: Brasiliense, 1986.

COUTINHO, Luciano. Política industrial é solução, não problema. Folha de São Paulo, São Paulo. 25 out 1998. dinheiro, p. 2.8. ERBER, Fábio S.; CASSIOLATO, José Eduardo. Política industrial: teoria e prática no Brasil e na OCDE. Revista de Economia Política. São Paulo, v. 17 n. 2 (66), p. 32-60, 1997.

FRISCHTAK, Cláudio Roberto. O que é política industrial? Rio de Janeiro: BNDES, 1993.

. Política industrial ativa em um mundo global. In: CASTRO, Antonio Barros de et al. O futuro da indústria no Brasil e no mundo: os desafios do século XXI. Rio de Janeiro: Campus, 1999. p.265-277.

KAPAZ, Emerson. Trata-se de engajar o país da globalização. Economia em Perspectiva. São Paulo, p.4-5, maio 1996.

KON, Anita. A urgência de uma política abrangente. Economia em Perspectiva. p.2-3, maio 1996.

LACERDA, Antonio Corrêa de. O impacto da globalização na economia brasileira. São Paulo: Contexto, 1998.

LAFER, Celso. A política industrial e de comércio exterior. In: VELLOSO, João Paulo dos Reis. A crise mundial e a nova agenda de crescimento. Rio de Janeiro: José Olympio, 1999. p. 225-236.

PINHEIRO, Armando Castelar. Perspectivas da política industrial. Boletim Conjuntura. IPEA, Brasília, n. $26,1994$.

SINGER, Paul. O capitalismo: sua evolução, sua lógica e sua dinâmica. São Paulo: Moderna, 1987.

STRACHMAN, Eduardo. Os fundamentos teóricos das políticas industriais. In: ENCONTRO NACIONAL DE ECONOMIA POLÍTICA, 4., 1999, Porto Alegre. Anais... Porto Alegre: [s.n.], 1999. 